\title{
Consolidation of Memory After its Reactivation: Involvement of $\beta$ Noradrenergic Receptors in the Late Phase
}

\author{
Pascal Roullet and Susan Sara ${ }^{\dagger}$ \\ Neuromodulation et Processus Cognitifs, Institut des Neurosciences, CNRS UMR 7624 \\ Université Pierre et Marie Curie, 9 quai St-Bernard, 75005 Paris, France
}

\section{SUMMARY}

Evidence is growing that the cAMP pathway through the cAMP responsive element binding protein (CREB) transcription factor plays an important role in long-term memory formation (LTM). To study the role of $\beta$-noradrenergic receptors, positively linked to the cAMP secondmessenger system, in the dynamics of LTM processes, we used a memory-reactivation paradigm because recent studies in our laboratory confirmed that reactivated memory is labile and undergoes an extended reconsolidation process. In an eight-arm maze, rats were trained to choose the same three baited arms; $24 \mathrm{hr}$ later, memory was reactivated and then the rats were injected intracerebroventricularly at $5 \mathrm{~min}, 30$ min, $60 \mathrm{~min}$, or $5 \mathrm{hr}$ later with the $\beta$-antagonist timolol or with saline. The results showed that injection of timolol induced amnesia only at the $60 \mathrm{~min}$ post-reactivation interval, whereas all control groups and groups that were timololinjected at other post-reactivation intervals displayed optimal retention. The delayed amnesic action of timolol suggests that $\beta$ noradrenergic receptors and the cAMP cascade are implicated in the late phase of reprocessing of a remembered event.

\section{KEY WORDS}

noradrenaline, reactivation, memory, radial maze, timolol, rat

\footnotetext{
${ }^{\dagger}$ Corresponding author

Phone: (33) 144273460

e-mail: sjsara@ccr.jussieu.fr
}

\section{INTRODUCTION}

Many years ago, Seymour Kety (1972) suggested that noradrenaline (NA) might promote memory processes by selectively reinforcing neural networks that are activated during an arousal state. Kety (1972, p. 383) further suggested that "release of catecholamines may favour consolidation of learning by stimulating protein synthesis..." through the actions of cyclic AMP on protein kinase. It has taken a quarter of a century for this hypothesis to gain a strong foothold, despite the demonstration of the permissive role of NA in models of synaptic plasticity as early as 1983 (Neuman \& Harley, 1983) Those studies clearly indicated that long-term potentiation in the dentate gyrus and the CA3 of the hippocampus is blocked by $\beta$ noradrenergic receptor antagonists (Harley \& Milway, 1986) and can be induced by $\beta$ agonists (Huang \& Kandel, 1996), working through the cAMP pathway (Stanton \& Sarvey, 1985).

A consensus is growing that the cAMP pathway through the cAMP-responsive element binding protein (CREB) transcription factor plays an important role in long-term memory formation across such diverse species as Aplysia, Drosophila, mice and rats (for review see Yin \& Tully, 1996). A remarkable consistency appears to exist concerning the time window of 3-6 hr after learning, when memory processes are vulnerable to interference with cAMP and protein kinases (Bernabeu et al., 1996, 1997). Moreover, studies of CREB-deficient transgenic mice suggest that such animals have intact short-term memories, but are unable to consolidate longer lasting memories (Bourtchuladze et al., 1994). Some of these studies confirmed earlier reports (Rose, 1991) that the intracellular cascade of events underlying the consolidation of 
memory takes place over an extended post-training time scale, up to several hours. These time windows are coherent with a large body of earlier literature showing that inhibition of protein synthesis by injection of antibiotics around the time of training induces a retrograde amnesia, whose onset is delayed by about $3 \mathrm{hr}$ (for an extensive review see Davis \& Squire, 1984).

The cAMP cascade is triggered either by massive entry of calcium into the cell, through the NMDA receptor, or through metabotropic receptors linked to adenylate cyclase by the Gs protein. $\beta$ noradrenergic receptors are part of this family of metabotropic receptors activating the cAMP cascade. Recently we observed that the blockade of $\beta$ receptors induces amnesia when the blocker is injected up to $2 \mathrm{hr}$ after a memory reactivation trial, in both aversive and appetitive tasks (Sara et al., 1997; Roullet et al., in press). In this experiment, reactivated memory proved to be even more susceptible than newly acquired memory to posttrial amnestic interventions. A previous study showed a temporal gradient of the efficacy of blockade of NMDA receptors in a memory reactivation paradigm (Przybyslawski \& Sara, 1997), similar to the effect of $\beta$-receptor blockade. Although both phamacological studies confirm the existence of an extended temporal gradient of consolidation, the systemic nature of the injections precludes any precise definition of the time window during which the drug exerts its effective action. In the present experiment, a $\beta$-receptor antagonist is administered directly into the lateral ventricles, at different intervals after the single reactivation trial, to ascertain if the $\beta$ receptor plays a role in the late, rather than in the early, stage of consolidation.

\section{MATERIALS AND METHODS}

Sixty-five male Sprague Dawley rats weighing 250-300 g (Iffa Credo, France) were housed in pairs in a vivarium at a constant temperature $\left(23 \pm 1^{\circ} \mathrm{C}\right)$ and light cycle (12 hr light: $12 \mathrm{hr}$ dark). Food and water were provided ad libitum. All animals were weighed and handled daily for 1 week before the beginning of the experiment and then were mildly food deprived to about $90 \%$ of their freely feeding weight. Chocolate-flavoured puffed rice cereal (Chocopops, Kellog's, France) was used as a reinforcement in the maze, and the rats were habituated to this food before training. The rats were pre-trained for 7 days on an eight-arm radial maze, elevated 0.6 meters from the floor. Three of the eight arms were baited, and the same three arms relative to the room were used for every trial. The maze was surrounded by a black curtain, and salient cues were hung on the curtain to serve as distal cues to aid in mapping of the environment. A radio, always situated in the same position in the room, provided an auditory cue. The experiment began with 2 days of pretraining, in which the reinforcement was available throughout the maze. The animals were then submitted to three trials daily (with a intertrial interval of $5 \mathrm{~min}$ ), consisting of placing the rat on the central platform and allowing free choice of visits to the alleys. After the three baited alleys were visited, the rat was placed in the animal room. A ceiling time of $5 \mathrm{~min}$ per trial was imposed. To ensure that performances were truly based on the integration of spatial information, the maze was rotated between every trial, both during the training and during the test sessions, thereby eliminating any possibility of using intramaze information. Two days after the last training session, the rats were anaesthetised with pento-barbital $(60 \mathrm{mg} / \mathrm{kg})$ and placed in a stereotaxic apparatus. The rats were implanted bilaterally with two 26gauge stainless-steel guide cannulae, placed 2-mm lateral to midline, $1.5-\mathrm{mm}$ posterior to bregma, and 3.2-mm under the skull surface. For the injection, an infusion cannula (36 gauge) was placed into the guide, projecting $1 \mathrm{~mm}$ beyond it into the ventricle. After a 10-day recovery period, the rats were retrained to a criterion of three consecutive trials with a maximum of one error in each trial.

The day after reaching the criterion, the rats were placed in the maze for a single reactivation trial. If still at criterion performance, the rat was given a single, bilateral intracerebroventricular (i.c.v.) injection with $4 \mu \mathrm{l} / \mathrm{hemisphere} \mathrm{of} \mathrm{timolol} \mathrm{(20}$ $\mu \mathrm{g} / \mathrm{kg}$ ) at $5,30,60$, or $300 \mathrm{~min}$ after the single trial, while controls were injected with $4 \mu$ l of saline. Each treatment group consisted of eight rats. To ensure that there were no initial differences among the treatment groups, group assignments were made 
according to the reactivation-trial performance. The rats were injected at a constant-flow rate over a period of $3 \mathrm{~min}$, and the infusion cannula was left in place for another $1 \mathrm{~min}$ after the injection. Performance on the maze was evaluated $24 \mathrm{~h}$ later (test day) with a session of one trial.

The exact sequence of alleys visited was noted, as well as the reference errors (visit to a nonbaited arm) and the working errors [repeated visit(s)]. The term total errors was defined as the addition of the two types of errors. The mean time per arm was also calculated.

The data were submitted to a $2 \times 4$ analysis of variance for repeated measures (ANOVA), with one factor the drug and the other the time of injection. Pair-wise comparisons, when indicated, were carried out by the post-hoc tukey test.

Three hours after the test trial, all rats received and i.c.v. infusion of methylene blue, were deeply anesthetized. The brains were removed, and the injection site was verified. Two rats were excluded from the analysis because the injection sites were incorrect, leaving two of the groups with seven rats each.

\section{RESULTS}

Timololol injected i.c.v. $60 \mathrm{~min}$ after the reactivation trial induced a memory deficit, detected when the rat was tested $24 \mathrm{hr}$ later. The total errors shown in Fig. 1 indicate that the performances of all groups were unchanged from the previous training session, with the exception of the group that had been treated with timolol $60 \mathrm{~min}$ after the reactivation trial. The ANOVA revealed a significant effect of the (a) time of injection $[\mathrm{F}(3,55)=2.87, \mathrm{p}=.044]$, (b) drug $[\mathrm{F}(1,55)=$ $4.06 \mathrm{p}=.048]$, and a marginal interaction $[\mathrm{F}(3,55)=$ $2.53, \mathrm{p}=.065]$. The time of injection and drug effects are due to the deficit in the drug-treated group at 60 min. This finding was confirmed by the Tukey

\section{Total errors}

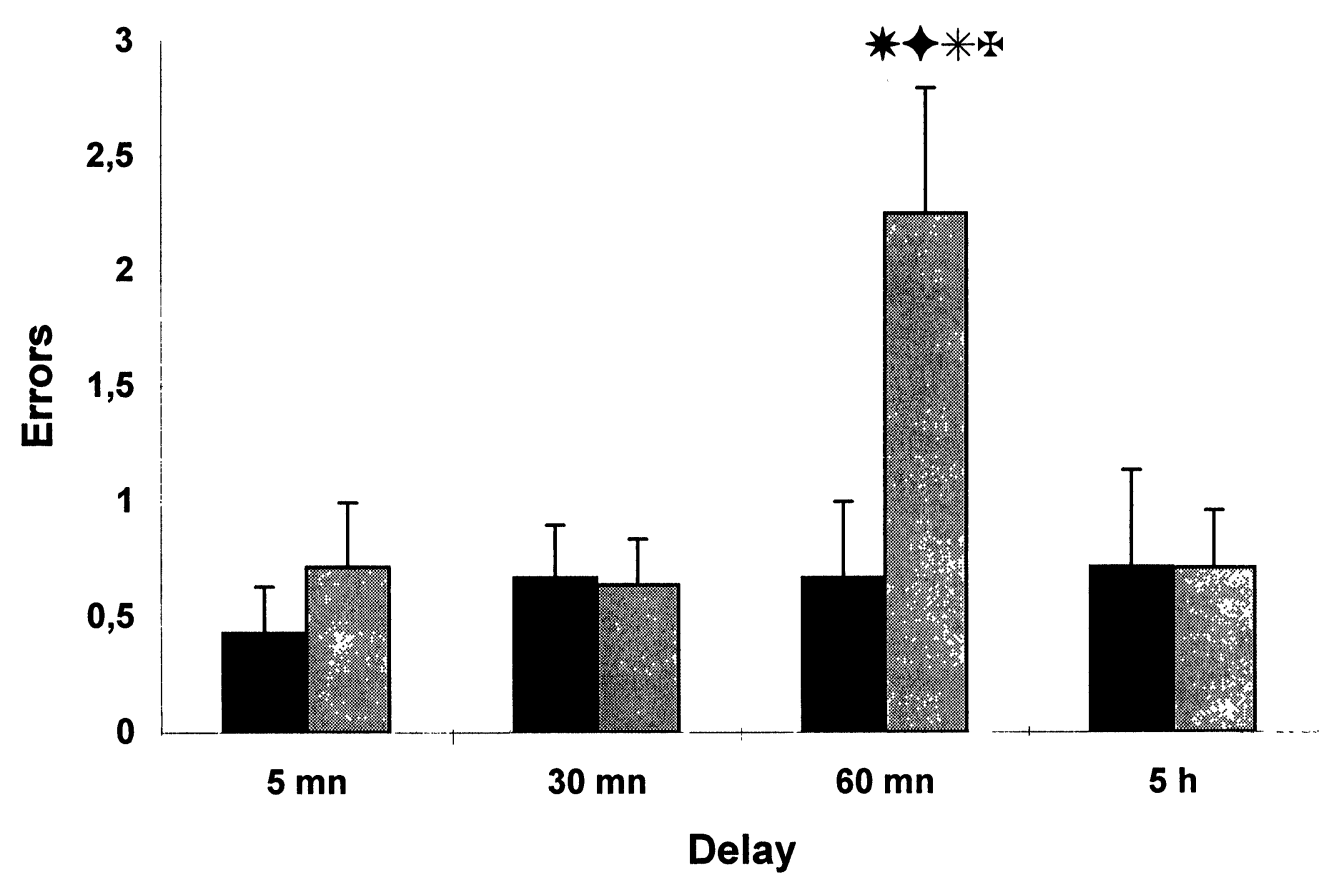

Fig. 1: Total number of errors (mean + s.e.m.). $\square$ : control. $\square$ : timolol. Rats were injected with timolol 60 min. after the reactivation trial made significantly more errors than those of all other groups. * $: p<.05$ compared with saline-injected group at the same delay; $\downarrow: \mathrm{p}<.01$ compared with timolol-injected group at the delay $5 \mathrm{~min}$; $*$ : $\mathrm{p}<.01$ compared with timolol injected group at the delay $30 \mathrm{~min}$.; : p<.01 compared with timolol-injected group at the delay $5 \mathrm{~h}$. 


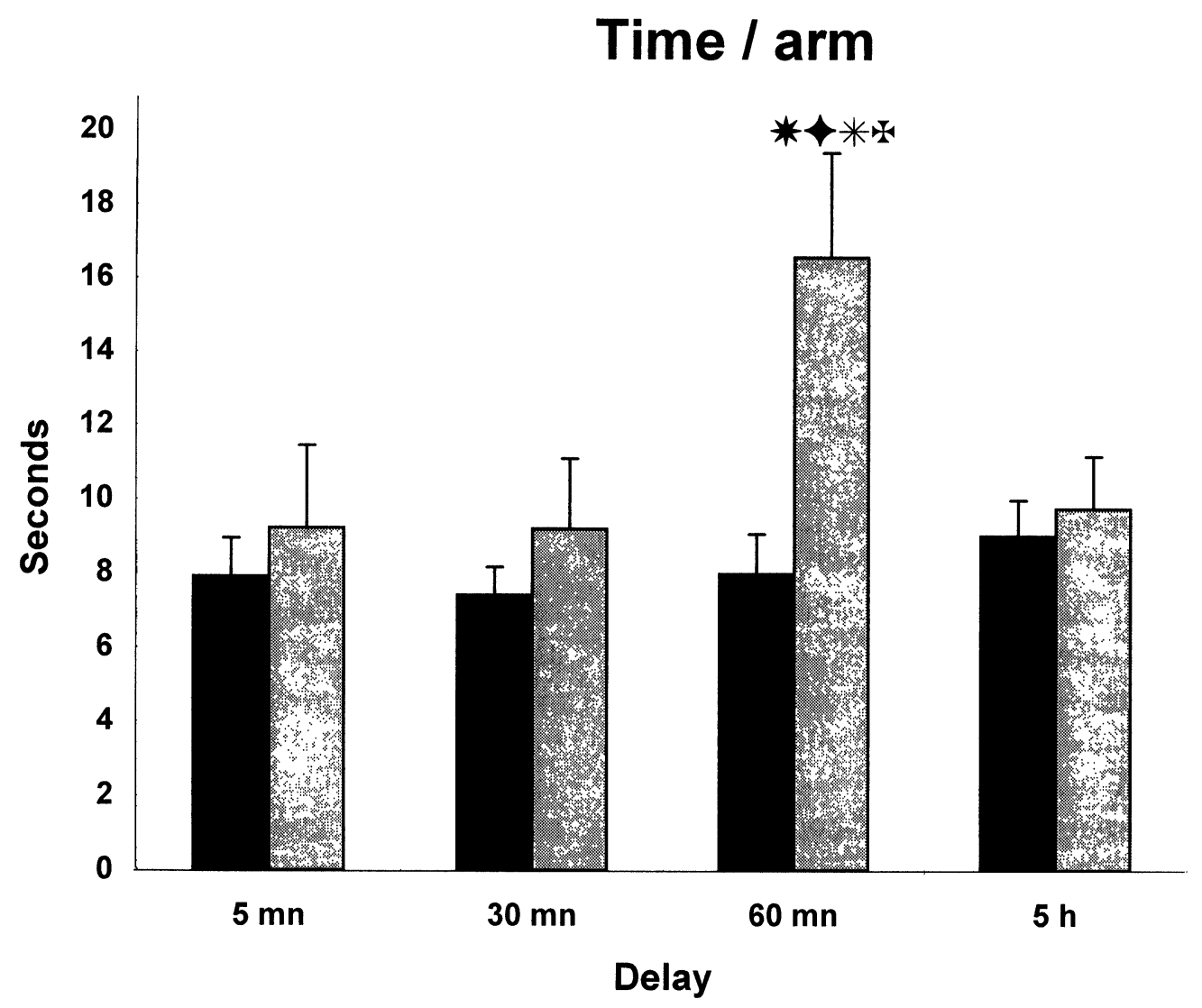

Fig. 2: Time per arm. (mean + s.e.m.). $\square$ : control. $\square$ : timolol. Rats injected with timolol 60 min. after the reactivation trial took significantly more time per arm than those of all other groups. * : p<.01 compared with saline group at the same delay; $\uparrow: \mathrm{p}<.01$ compared with timolol injected group at the delay $5 \mathrm{~min}$; $*$ : $\mathrm{p}<.05$ compared with timolol injected group at the delay $30 \mathrm{~min}$; $: \mathrm{p}<.05$ compared with timolol injected group at the delay $5 \mathrm{~h}$.

protected $\mathrm{t}$-tests showing that this group made significantly more errors than did the control group injected with saline at $60 \mathrm{~min}(\mathrm{t}=2.41, \mathrm{p}<.05)$. This group also made significantly more errors than groups treated with timolol at $5 \mathrm{~min}, 30 \mathrm{~min}$, or $5 \mathrm{hr}$ after the reactivation trial $(\mathrm{t}=2.70, \mathrm{p}<.01 ; \mathrm{t}=3.26$, $\mathrm{p}<.01$ and $\mathrm{t}=3.01, \mathrm{p}<.01$, respectively). No other differences between the groups were found.

For the behavioural index time-per-arm, a significant effect of drug $[F(1,55)=5.93, p=.018]$ occurred, which is due to differences at the $60 \mathrm{~min}$ time point, as shown in Fig. 2. Post-hoc analysis showed a significant difference between saline and timolol at the delay of $60 \min (t=3.39, p<.01)$ and with the three other groups injected with timolol (Tukey, $\mathrm{t}=2.99, \mathrm{p}<.01 ; \mathrm{t}=2.43, \mathrm{p}<.05 ; \mathrm{t}=2.56$, $\mathrm{p}<.05$; for $5 \mathrm{~min}, 30 \mathrm{~min}$, and $5 \mathrm{~h}$, respectively), with no other between group differences.

\section{DISCUSSION}

The results of the present study show that a $\beta$ noradrenergic antagonist provokes amnesia for a well-consolidated memory when it is reactivated before drug treatment. The most remarkable result of this experiment is that timolol had an amnestic effect only when injected i.c.v. $60 \mathrm{~min}$ after the reactivation trial. No effect was seen when it was injected sooner (at 5 or $30 \mathrm{~min}$ ) or later (at $5 \mathrm{~h}$ ) after a reactivation trial. The lack of effect at other injection times indicates that the effect of timolol cannot be due to a pro-active, long-term, nonspecific effect on behaviour $24 \mathrm{~h}$ later, but rather that timolol acts on a reactivated memory within a very specific time window. Previous experiments in our laboratory, using systemic injections of the $\beta$-antagonist propranolol, confirmed that the 
amnestic effect is indeed limited to a reactivated memory, as no effect of the injection occurred when it was made in the absence of a trial, that is, in the vivarium, in rats that had been submitted to exactly the same previous learning experience.

At the 60-min delay, timolol also increased the time per arm. Again, this result cannot be due to an effect of timolol on locomotor activity, as no such effect occurred in the three other timolol-injected groups. Moreover, although the latency in entering the first arm was not affected, after making one or two errors, the rats were slow to make choices.

Earlier experiments had established that a temporally graded amnesia can be induced by a variety of amnestic agents after a reactivation trial (Misanin et al, 1968; Lewis et al., 1972; Lewis \& Bregman, 1973; Schneider \& Sherman, 1968). Since then, occasional reports have been published in the literature about such a phenomenon. For example, the electrical stimulation of the amygdala after reactivation of a tone-shock pairing produces temporally graded amnesia (Devietti \& Kirkpatrick, 1976). In a more recent study, rats were trained in a passive avoidance procedure and then re-exposed to either the conditioned stimulus or the unconditioned stimulus $48 \mathrm{hr}$ after training. Functional blockade of the parabrachial nucleus by tetrodotoxin after either reactivation-procedure-induced retrograde amnesia (Bucherelli \& Tassoni, 1992). In a recent experiment in our laboratory, an amnesia was obtained with MK-801 treatment when a systemic injection was made up to 90 min after a reactivation trial in the same task as that used in the present experiments (Przybyslawski \& Sara, 1997). Such results suggest that memory is labile not only immediately after acquisition but also whenever memory is in an active state.

The results of the present experiment, in which timolol had no action at $30 \mathrm{~min}$ but provoked an unambiguous amnesia if injected $60 \mathrm{~min}$ after reactivation, underlines the importance of the temporal dynamics of memory consolidation. This finding also suggests that $\beta$ noradrenergic receptors are implicated during a very precise time window. This time frame is compatible with recent reports from Izquierdo's laboratory showing delayed enhancement of cAMP and p-CREB immunoreactivity in the hippocampus 3 to $6 \mathrm{hr}$ after passive avoidance training (Bernabeu et al., 1996, 1997). Such delayed activation of the $\beta$ receptors might serve to reinforce or to prolong, through the Gs protein adenylate cyclase pathway, the NMDA receptor-dependent, cAMP cascade that is initiated at the time of learning. Thus, sustained postacquisition neuromodulatory influences would provide the signal for the formation of long-term memories, the molecular switch recently proposed by Yin \& Tully (1996). The delayed amnesic action of timolol after memory reactivation suggests that $\beta$ noradrenergic receptors and the cAMP cascade are implicated in the late phase of reprocessing of a remembered event as well.

\section{ACKNOWLEDGEMENT}

This research was supported by the European Science Foundation Programme on the Neural Mechanisms of Learning and Memory and by the CNRS UMR 7624. We thank Celine Perrier for technical assistance.

\section{REFERENCES}

Bernabeu R, Schmitz P, Faillace MP, Izquierdo I, Medina $\sqrt{ }$. Hippocampal cGMP and cAMP are differentially involved in memory processing of inhibitory avoidance learning. Neuroreport 1996; 7: 585-588.

Bernabeu R, Bevilaqua L, Ardenghi P, Bromberg E, Schmitz, $P$, Bianchin, et al. Involvement of hippocampal cAMP/ cAMP-dependent protein kinase signalling pathways in a late memory consolidation phase of aversively motivated learning in rats. Proc Natl Acad Sci USA 1997; 94: 7041-7046.

Bourtchuladze R, Frenguelli B, Blendy J, Cioffi D, Schutz G, Silva AJ. Deficient long-term memory in mice with a targeted mutation of the cAMP-responsive elementbinding protein. Cell 1994; 79: 59-68.

Bucherelli C, Tassoni G. Engram activation reinstates the susceptibility of consolidated memory traces to retrograde amnesia by functional blockade of parabrachial nuclei. Behav Brain Res 1992; 51: 61-65.

Davis HP, Squire LR. Protein synthesis and memory. Psychol Bull 1984; 3: 518-559.

DeVietti TL, Kirkpatrick BR. The amnesia gradient: inadequate as evidence for a memory consolidation process. Science 1976; 194: 438-440.

Harley CW, Milway CW. Glutamate ejection in the locus coeruleus enhances the perforant path-evoked popula- 
tion spike in the dentate gyrus. Exp. Brain Res 1986; 63: 143-150.

Huang YY, Kandel ER. Modulation of both the early and the late phase of mossy fiber LTP by the activation of b-adrenergic receptors. Neuron 1996; 16: 611-617.

Kety SS. The possible role of the adrenergic systems of the cortex in learning. In: Rec Publ Assoc Res Nerv Ment Dis $1972 ; 376-389$.

Lewis D, Bregman N, Mahan J. Cue-dependant amnesia in rats, J Comp Physiol 1972; 81: 243-247.

Lewis DJ, Bregman NJ. Source of cues for cue-dependent amnesia in rats. J Comp Physiol Psychol 1973; 85: 421-426.

Lewis DJ. Psychobiology of active and inactive memory. Psychol Bull 1979; 86: 1054-1083.

Misanin JR, Miller RR, Lewis DJ. Retrograde amnesia produced by electroconvulsive shock after reactivation of consolidated memory trace, Science 1968; 160: 554555.

Neuman RS, Harley CW. Long-lasting potentiation of the dentate gyrus population spike by norepinephrine.
Brain Res 1983; 273:162-165.

Przybyslawski J, Sara SJ. Reconsolidation of memory after its reactivation. Behav. Brain Res1997; 84: 241-246.

Rose SPR. How chicks make memories: the cellular cascade from c-fos to dendritic remodelling. Trends Neurosci 1991; 14: 390-397.

Sara SJ, Roullet P, Przybyslawski J. Reconsolidation after reactivation of memory: Role of $\beta$-noradrenergic receptors, Soc Neurosci Abstr 1997; 624.25.

Schneider AM, Sherman W. Amnesia: A function of the temporal relation of footshock to electroconvulsive shock. Science 1968; 159: 219-221.

Sekiguchi T, Yamada A, Suzuki H. Reactivation-dependent changes in memory states in the terrestial slug Limax flavus. Learn Mem 1997; 4: 356-364.

Stanton PK, Sarvey JM. The effect of high-frequency electrical stimulation and norepinephrine on cyclic AMP levels in normal versus norepinephrine-depleted rat hippocampal slices. Brain Res 1985; 358: 343-348.

Yin JCP, Tully T. CREB and the formation of long-term memory. Curr Opin Neurobiol 1996; 6: 264-268. 

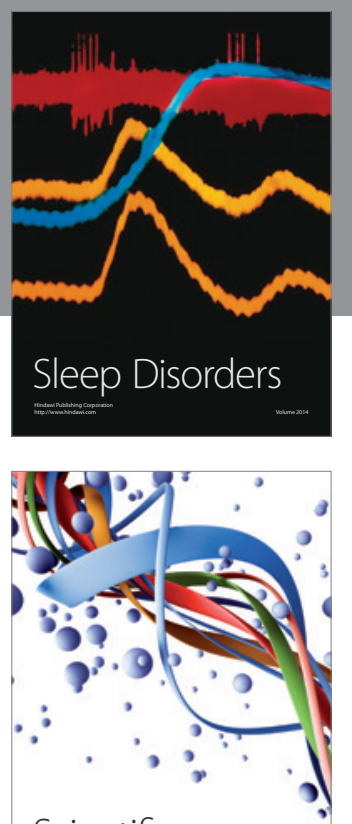

Scientifica
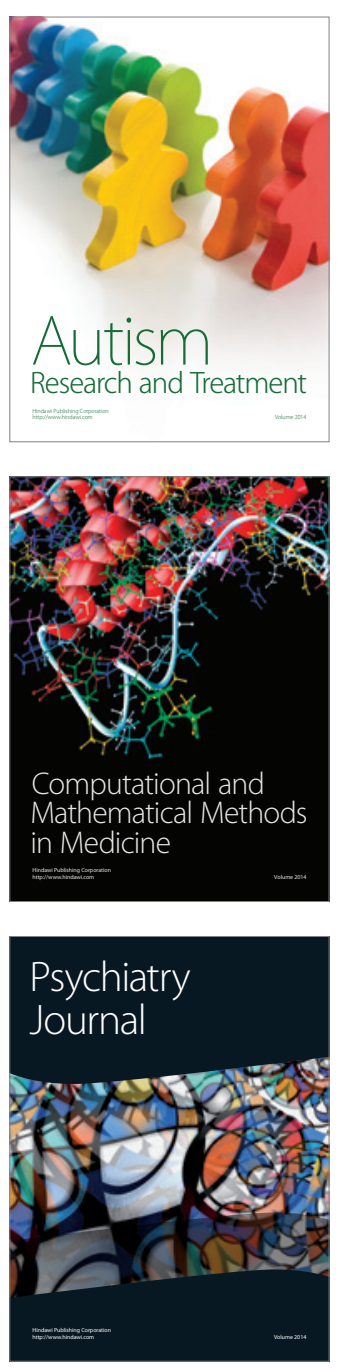
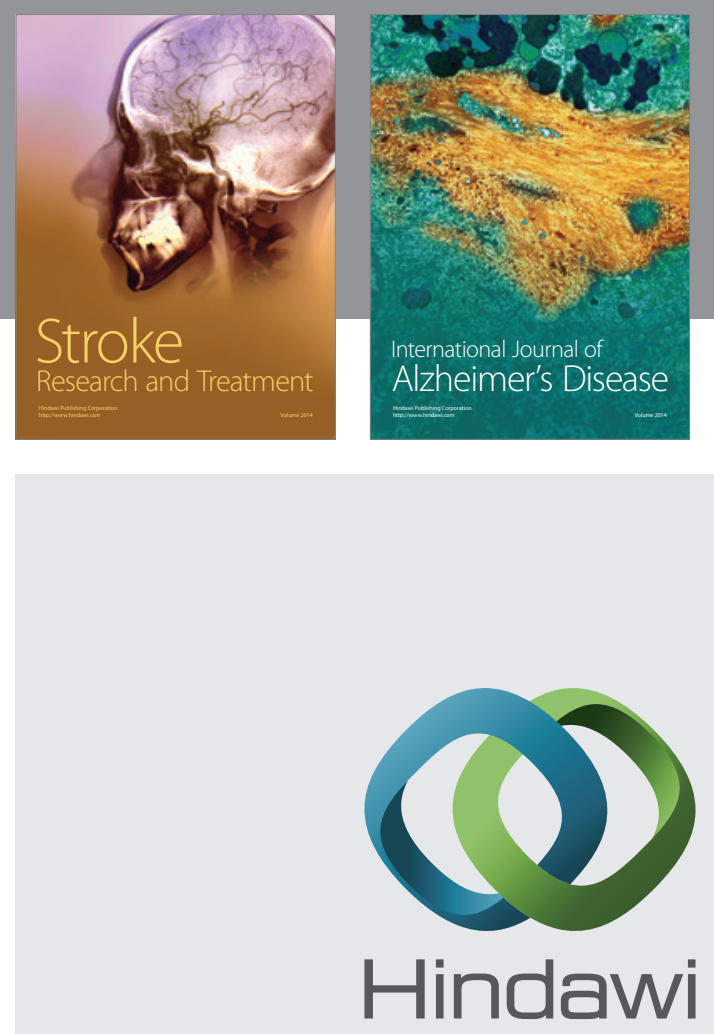

Submit your manuscripts at

http://www.hindawi.com
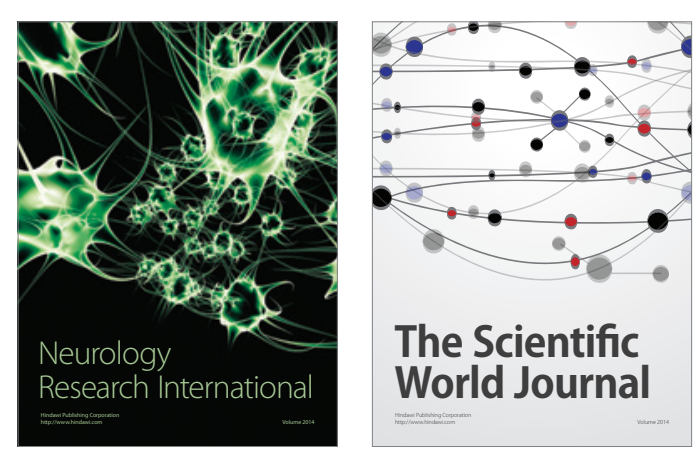

The Scientific World Journal

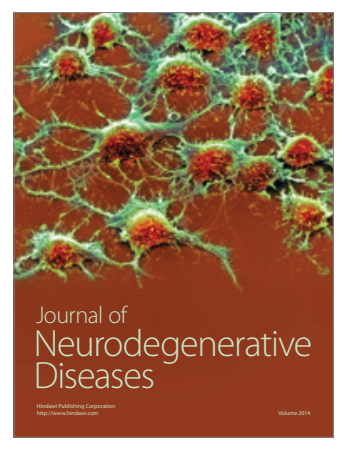

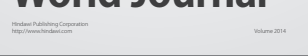

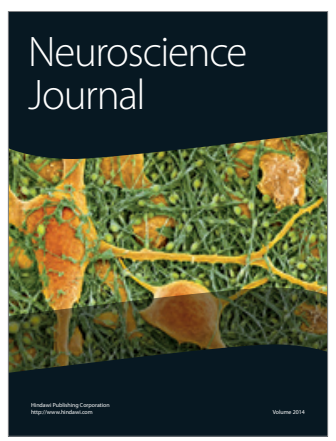

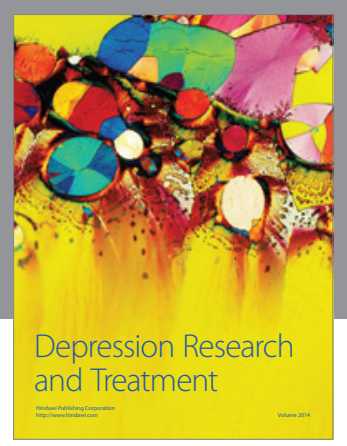
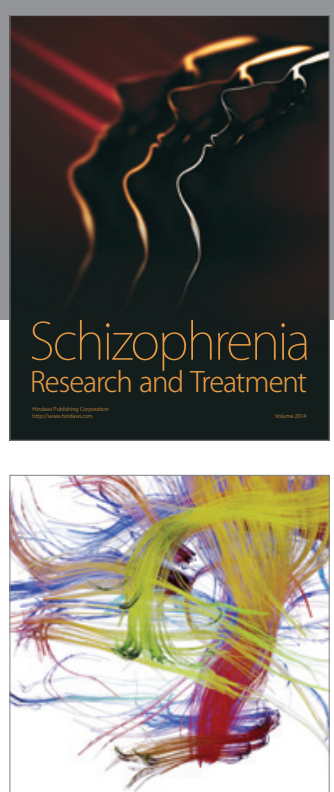

Brain Science

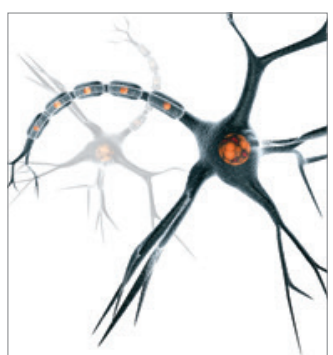

Neural Plasticity
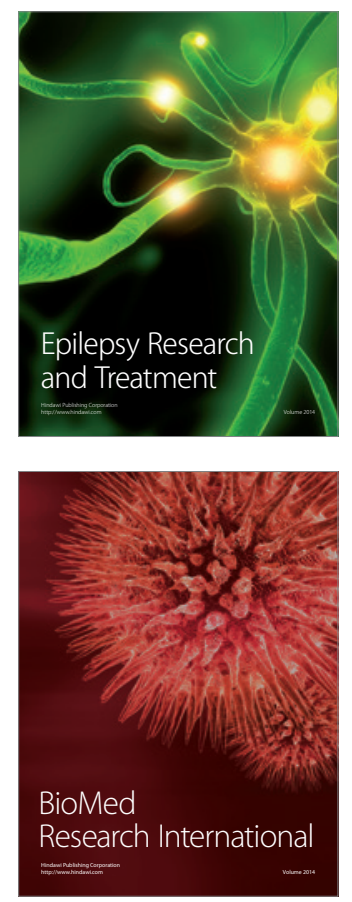

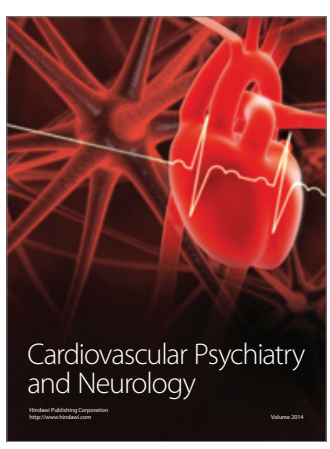

Parkinson's

Disease
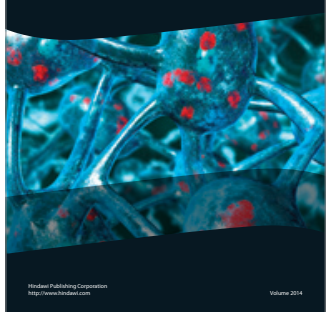